\title{
Research on Design of Coal Logistics Platform Based on User Experience*
}

\author{
Yan Shen \\ Art School \\ Northwest University \\ Xi'an, China 710000
}

\begin{abstract}
With the increasing prosperity of information technology and extensive application of mobile terminal equipment, truck drivers will not adopt offline method, the relatively backward one, to acquire the coal freight information, but use mobile Internet platform to obtain coal supply information. This emerging mode is driven by mobile terminal devices, which imperceptibly affect the drivers' delivery mode. Truck drivers are the main transport force of retail coal freight, as a special user group, they are different from the ordinary freight drivers. Taking coal logistics supply as the central demand, this paper studies truck drivers' demand for basic functions of mobile terminal product and their relevant cognitive level and usage habits, and designs products that meet the needs of coal logistics truck driver users based on the modern market demand of coal freight logistics industry.
\end{abstract}

Keywords-user experience; coal freight; mobile terminal; interaction design

\section{INTRODUCTION}

China needs more than 3 billion tons of coal every year. Today, with the increasing prosperity of information technology and extensive application of mobile terminal equipment, truck drivers will not adopt offline method, the relatively backward one, to acquire the coal freight information, but use mobile Internet platform to obtain coal supply information. This emerging mode is driven by mobile terminal devices, which imperceptibly affect the drivers' delivery mode. Truck drivers are the main transport force of retail coal freight, as a special user group, they are different from the ordinary freight drivers. Taking coal logistics supply as the central demand, this paper studies truck drivers' demand for basic functions of mobile terminal product and their relevant cognitive level and usage habits, and designs products that meet the needs of coal logistics truck driver users based on the modern market demand of coal freight logistics industry.

\section{ANALYSIS OF USER CHARACTERISTICS OF COAL LOGISTICS PLATFORM}

The living space of the driver group should receive more in-depth attention and research, and this special group has its

*Special Scientific Research Program of Shaanxi Education Department in 2018 (Humanities and Social Sciences Category) Project Title: Research on Interaction Design of Coal Logistics Platform in Shaanxi Based on User Experience. Project No.: 18JK0725. own characteristics. Due to the particularity of work and a series of physiological and psychological changes, in order to ensure the good availability, experience and feeling of the interface of coal logistics platform, it is critical and necessary to explore the psychological characteristics of truck drivers.

\section{A. Physiological Characteristics of Drivers}

At present, a large part of truck drivers in China are selfemployed and engaged in logistics transportation. However, as a result of the limitations of some factors, such as relatively poor risk resistance of individual operation, unstable supply, low bargaining power, relatively backward means of delivery, and so on, some drivers' survival situation is worrying. From the perspective of quality of life, it is mainly manifested in poor living habits, irregular living and rest, overload work and so on. Affected by working environment, the working environment of coal logistics drivers is relatively bad, and they are on the highway all the year round and their work content is relatively monotonous. Besides, truck drivers shoulder a huge freight task, so that they are prone to nervousness and anxiety. On account of the limitations of work, most of truck drivers lack the opportunity to communicate with the outside world, so that they have certain physical and psychological problems, and all these factors seriously affect their physical and mental health.

\section{B. Psychological Characteristics of Drivers}

First, truck drivers are realistic and seek for low price. Because of the difficulty of making money, truck drivers hope that the transportation costs can be increased and the government can provide them with corresponding preferential policies, such as exempting from information service charges of freight, providing certain insurance services, and so on.

Second, truck drivers pursue simplicity and convenience. Drivers prefer simpler and easier-to-understand one in the use of products, and generally reject the more complex use flow of the platform. With certain guiding function, the products can facilitate driver users operate them by themselves. Therefore, those platforms that are easy to use, easy to learn, and easy to operate are more favored by drivers.

Third, truck drivers' mood fluctuates greatly. There is no timetable for trucks, so truck drivers may stop working at any time during transportation due to the lack of high quality 
supply, which increases their economic losses and psychological impact.

\section{USER REQUIREMENTS ANALYSIS OF COAL LOGISTICS PLATFORM}

Providing the high quality supply is the central task of user requirements in the design of coal logistics platform, the coal logistics platform is a mobile Internet platform where coal bosses and drivers directly contact. The most basic function of the platform is that the shipper delivers goods and the driver transports goods. For drivers, the central task of demand is to look for high-quality supply of goods, and user demands for the design of coal logistics platform are centered on the central demand of looking for supply of goods. The market of driver users on the coal logistics platform mainly can be divided into the following types:

- Explicit users: when drivers visit the platform, they can find that the user has a clear goal and a certain purpose. For example, drivers can find the appropriate supply of goods through conditional screening or order subscription, set the starting city and screen the frequently-used arrival city, and then grab the order.

- Unclear users: drivers visit the platform and users have the demands of transporting goods, but there are no clear targets of transporting goods. Under such condition, the drivers need the guidance of platform to meet the demands of transporting goods. For example, the goods can be divided into high-quality supply of goods, recommended supply of goods and common supply of goods. The drivers can select the most appropriate supply of goods and grab the order.

- $\quad$ Potential users: drivers visit the platform but there are no demands of transporting goods from users. It is the platform that stimulates the users to have the demands of transporting goods. The platform always conducts advertising promotion, lottery and snatching a red envelope to attract the users and makes them have such demands. And this kind of users can be easily transformed the active users of coal logistics platform.

For different types of target users, the operation mode and process of coal logistics platform are different. In the design of coal logistics platform, we have to consider the needs of different types of users to provide a good experience to all uses. With the rapid development and expansion of the Internet and modern information technology, the traditional logistics coal industry has also joined the Internet. Accompanied by continuous development of the Internet, uses' product cognition level has been constantly improved, and the design of coal logistics platform based on the potential needs of users also has a certain foundation. Goods-transportation of coal logistics drivers is a process with long procedure and many steps. The different targeted cities and type of goods will lead to different demands of users for the application.

\section{The VAlue of USER EXPerience IN THE Design OF COAL LOGISTICS PLATFORM}

In the process of designing the platform, we may often ignore the important factor of user experience, but it is critical and related to the success or failure of the product. What the user experience pays attention to is not how to use the product, but "how the product interacts with the outside world and how it works", that is, how we "contact" and "use" it in our words. User experience is what users feel and think in using products and receiving services in actual needs. This kind of experience is both a rational judgment and an emotional aftertaste. Regardless of the type of product, users tend to focus on the nuances, therefore, we should pay special attention to products' user experience.

User experience emphasizes that the design is based on user needs. Good product design can not only meet the needs of users, but also get their attention and trust. Mobile terminal products are presented in the form of interface. As the medium of communication between users and products, the interface is also an interaction between users and designers in a sense. The coal logistics platform is completed based on the interface interaction design. The coal logistics platform meets the needs of users looking for high-quality supply of goods. Users can complete the whole process of goods transportation in the platform including order grabbing, goods transportation, payment, navigation and evaluation. We know that from the introduction of user experience literature, Jesse James Garrett divides the factors of experience into five aspects: strategic layer, scope layer, structure layer, framework layer, and presentation layer ${ }^{1}$. This layer is critical and is the foundation for product success. Each of these five layers has a continuing relationship with the previous layer, and user needs also involve every layer of the five layers. The potential needs of users play a role in improving the availability of users, which is a key factor in interaction design and occupies a vital role in the overall design of products. We can improve the availability of products from the following aspects: follow the users' behavior habits, make products easy to be learnt and understood, reduce users' operating cost, reduce the memory burden and bring a good user experience to the user. Each truck driver of coal logistics efficiently and happily completes goods transportation, which can reduce the loss of users, enhance the competitive advantage and improve economic benefits.

In summary, "coal logistics platform user experience" refers to what users long for, think and consider in the process of goods transportation on the coal logistics platform. It's a purely subjective experience and affected by many factors, such as whether it meets the users' potential needs, running speed of clients, speed of the network used, functions of products themselves, and so on. Evaluation refers to the use of prototypes and products for certain evaluation and measurement. When evaluating, we can observe many experience problems during use. Relevant evaluation can provide certain basis, scheme and suggestion for product improvement. To a great extent, prototype design and

Garrett J J. User Experience Elements [M] . Translated by Fan Xiaoyan. China Machine Press. 2007 
evaluation are constantly changing and updating ${ }^{2}$. Testing availability is very important when we conduct system research and development. Availability refers to observing whether a product can achieve the purpose of ease of use based on the human level, so as to truly meet the needs of users. Usability means that relevant operations can make the users' memory and learning easier and leave some space for users to make mistakes. We should select a more reasonable evaluation method based on the focus, and then evaluate whether the user is really satisfied.

In light of the user demand situation of coal logistics platform, the author has made many explorations. The logistics platform should be based on user experience. In terms of user experience, we not only focus on the interface interaction, but also explore the potential needs of users. What we are concerned about is that user experience should not only focus on interface interaction, but also tap the potential needs of users. Under the network environment, the electronic platform has been popularized, and logistics has also been greatly developed. Logistics platform has been more used for life, and the traditional coal industry and logistics platform are integrated. How to provide users with a good experience of order grabbing and goods transportation is also a great challenge for the coal logistics platform.

\section{CONCLUSION}

Many traditional industries have begun to transform, and people's consciousness has undergone earth-shaking changes. The way users get information is no longer a relatively backward traditional offline mode. Instead, they complete transactions online by using the mobile Internet platform. What's more, the emerging model of online access to information has also been accepted by vast driver users, and its speed of change is constantly accelerating. In particular, today, as people pay more and more attention to user experience, new technologies are emerging in an endless stream. In order to serve users in a better and more humanized way, the online platform of coal logistics is not only a modern Internet development trend, but also an important component of the market. In the context of such environment, this paper studies the application software design of coal logistics platform based on user experience.

Only by deeply understanding the needs of users can we define the design direction of the product. We should make an analysis for competitive products of existing coal logistics platform cases, learn from the experience of predecessors, apply excellent interactive methods to their own products, summarize the shortcomings and avoid wrong interaction method in product design. Meanwhile, we also should analyze user characteristics, summarize users' habits through user research, understand users' needs, and lay the foundation for follow-up research. The author hopes that the research results of this paper can play a role in the establishment and development of Internet coal logistics information platform in China. In order to maximize and optimize the effectiveness of coal logistics platform from design to development, the whole

2 Liu Ying. Availability Evaluation and Method of Human-Computer Interactive Interface [J]. Ergonomics 2002. team needs to cooperate actively. Both the design of mobile terminal application and coal logistics platform are not immutable. We need to advance with the times and keep exploring in the future study and work.

\section{REFERENCES}

[1] Garrett J J. User Experience Elements [M]. Translated by Fan Xiaoyan. China Machine Press. 2007

[2] Liu Ying. Availability Evaluation and Method of Human-Computer Interactive Interface [J]. Ergonomics 2002. 